\title{
Low and Highly Skilled Labor Immigration and Wage Inequality
}

\author{
Beate Wojtyniak ${ }^{1}$, Udo Broll ${ }^{2}$, Sugata Marjit ${ }^{3}$ \\ ${ }^{1}$ Applied University Saarbrücken, Saarbrücken, Germany \\ ${ }^{2}$ Department of Economics, Technische Universität Dresden, Dresden, Germany \\ ${ }^{3}$ Centre for Studies in Social Sciences, Calcutta, India \\ E-mail: udo.broll@tu-dresden.de \\ Received October 26, 2009; revised December 9, 2009; accepted December 10, 2009
}

\begin{abstract}
Fears of rising income inequalities loom large in recent discussions of how globalization and in particular migration are affecting economies and societies [1]. This paper addresses the question how labor immigration is related to wage inequality by using a specific-factors trade model. We show that the impact of immigration of low or highly skilled labor on wage inequality depends mainly on the capital intensity of the industry in which labor immigrates.
\end{abstract}

Keywords: Immigration, Skilled and Unskilled Labor, Wage Inequality

\section{Introduction}

Migration has always formed a topic of serious economic interest. However, the world appears to be on the edge of a new era in labor migration, since volume of migration has increased, more home and host countries have been added, and new types of labor migration have emerged. The global stock of migrants about 191 million doubled over the past 40 years which made migration the top of the national and international policy agenda [2].

Globalization is often claimed as being one of the driving forces behind the increasing labor migration $[1,3]$. Decreasing transportation costs, the emergence of transnational networks and the rapid growth of communication technologies, in addition to sustained growth in international trade as well as foreign direct investment and the trend of international outsourcing, indicating integrated world markets, all that contributes to the increasing movement of both low and highly skilled workers [4].

Although workers do not only migrate northward or into high income countries, fears of mass immigration

\footnotetext{
${ }^{1}$ The countries of South Africa have been sending and receiving workers, especially the mining centers in the region, Namibia, South Africa Zambia and Zimbabwe. This region recently undergoes an increasing number of migrants from Asia [5].

${ }^{2}$ See, for example, OECD, 2008b. According to the World Bank [6], over fifty percent of college graduates from Central America and the Caribbean leave their countries and in some of them, the figure is as high as eighty percent, i.e. eight out of ten Haitians and Jamaicans who have college degrees live outside their home country.
}

often engross the dicussions. However, in 2005, 62 million of migrants coming from developing countries migrate to industrialized countries whereas 61 million went to developing countries [2]. Neighboring countries or countries within the region are still important destinations for low skilled migrants working abroad. The increasing size of migration goes along with more countries becoming host countries. But, seasonal workers, mine workers as well as maids belonging to the group of low skilled workers ${ }^{1}$ seldom find a ready welcome. Host countries tend to prefer other types of migrants. The movement of highly skilled professionals towards the developed countries, widely known as brain drain ${ }^{2}$ for the countries of departure, and seen as brain gain for the countries of arrival is highly welcomed and recently undergoes further promotion by special immi- gration schemes. Some studies already see a competition for the skilled between the developed countries due to demographic and economic challenges [4,7].

According to the International Labour Organization [8], about half of the migrants moving 2006 were economically active at all rungs of the job ladder. Labor immigration affects the economy and development in a multiplex way, depending on features of labor markets, structures of production, and number of migrants $[6,4]$ and is often claimed to change the status of wages in general for both migrants and natives. Moreover, various studies indicate that globalization has gone along with increasing wage inequality. The increasing premiums on skills compared to constant or even decreasing wages have led to considerable public 
and scholarly debates ${ }^{3}$ [9]. Thus, the effect of immigration on host countries wages takes on greater significance.

The rest of the paper is organized as follows. Section 2 deals with wage inequality in developing countries. Section 3 develops a general equilibrium model with highly skilled and low skilled labor. In section 4 the main findings are derived and discussed. The final section 5 concludes.

\section{Wage Inequality in Developing Countries}

The scanty theoretical literature explaining the wage inequality in the Southern countries includes works of Marjit et al., Marjit and Acharyya [10-12]. They reveal unfavorable effects of trade liberalization and inflows of foreign capital on less developed countries, given the specific structural characteristics of developing countries, such as imperfections and distortions in the goods and labor markets and the degree of global capital mobility. More recently, Marjit and Kar [13], Yabuuchi and Chaudhuri [9] addressed the questions of wage inequalities and different types of labor. They find that emigration of low skilled workers increases the wage inequality if the capital's shares is greater in the skilled-using labor sector ${ }^{4}$. Whereas those studies focus on emigration, Johannsson and Weiler [14] highlight the effect of immigration on wage inequality of natives. They find evidence that growing relative inflows of unskilled workers increase wage inequalities within the USA, and that the impact on native wage inequality is even stronger as the overall effect.They estimate that a 10 percent increase of the skill-low skill ratio between immigrants and natives leads to a 0.22 percent increase in the wage inequality ratio.

This paper addresses the question how immigration of various types of workers affects the overall wage inequality within host countries in a general equilibrium model. We use the specific-factors model related to Jones [15] with two goods and three inputs. Whereas capital is mobile between the sectors, labor is specific. We interpret labor as being industry specific with skills as human capital which needs time to be acquired ${ }^{5}$.

In the specific-factors trade model, immigration of either high or low skilled workers leads to a decline in wages and an increase in the return of capital. Because ca-

${ }^{3}$ For a study explaining the interaction between the wage inequality and the supply of highly skilled labor, see J. Meckl, and S. Zink, [16].

${ }^{4}$ Yabuuchi and Chaudhuri [9] develop a model that incorporates diverse trade pattern and the imperfection of labor markets within a general equilibrium. Although focusing on emigration they expand their findings on immigration and argue that immigration is likely to have an unfavorable effect on wage inequality independently on factor allocation.

${ }^{5}$ In the literature on trade and development, a developing country is seen as exporter of agricultural commodities and importer of manufacturing goods. These types of commodities completely differ in production and require two different types of capital. However, we assume immigration in either commercial agricultural sectors and non-agricultural sectors and hence justify the use of homogeneous capital in two sectors. pital is mobile between the skilled and the low skilledusing sector, immigration that causes reallocation of capital will always affect the wage of the other sector. The main findings are that immigration leads to decreasing wages and increasing capital incomes which might explain the increasing income inequalities in both developing and developed countries. Moreover, this little theoretical study helps to explain how wage inequality is affected by immigration. We find that as long as the capital share in the skilled-using sector exceeds that in the low-skilled-using sector, immigration of both skilled and low skilled workers may reduce the wage-gap. On the other hand, capital income is likely to win from immigration independently on type of migration ${ }^{6}$.

\section{Specific-Factors Trade Model and Immigration}

We use a specific-factors model for a small open economy on a comparative static approach, i.e. initially there is no international labor immigration. There are two goods, $X$ and $Y$. Good $X$ is produced by using low skilled labor, $L$, and good $Y$ by using highly skilled labor, $S$. Highly skilled and low skilled labor are different inputs, i.e. labor is specific by industry. This fact points out that wages differ across industries. The production of both goods needs capital, $K$. Only capital is homogeneous and common to the two production functions. Therefore we have $X=F_{x}\left(K_{x}, L\right)$ and $Y=F_{y}\left(K_{y}, S\right)$. Production functions exhibit constant returns to scale and diminishing marginal productivities ${ }^{7}$. Goods are traded freely and prices for these goods are given exogenously in the rest of the world ${ }^{8}$.

The following set of equations describes the market equilibrium. With perfect competition in goods and factor markets, factor markets clear and cost for each commodity is driven down to price.

$$
\begin{aligned}
& a_{L X}\left(w, w_{s}, r\right) w+a_{K X}\left(w, w_{s}, r\right) r=p_{x}, \\
& a_{S Y}\left(w, w_{s}, r\right) w_{s}+a_{K Y}\left(w, w_{s}, r\right) r=p_{y} .
\end{aligned}
$$

Wages and the rental rate of capital are denoted by $w$, $w_{s}$ and $r$. The cost minimizing input-output coefficients in industry $X$ are $a_{L X}(\cdot), a_{K X}(\cdot)$. The same variables are used for the $Y$ sector, with $S$ and $Y$ as indices, $a_{L Y}(\cdot), a_{K Y}(\cdot)$. Capital and labor are fully em-

${ }^{6}$ The results have important policy implications for receiving countries. Although the immigration of low or medium skilled workers are often blamed for the increase in wage inequalities, the immigration of seasonal workers, maids and nurses seems to have no deteriorating effect on wage inequalities given those sectors are producing at a low relatively capital intensity.

${ }^{7}$ Sufficient conditions for an interior optimal solution, the Inada conditions, are fulfilled.

${ }^{8}$ The model can be used to study international trade in which talent labor form the basis for comparative advantage. 
ployed. Hence we obtain

$$
\begin{gathered}
a_{L X}\left(w, w_{s}, r\right) X=L, \\
a_{S Y}\left(w, w_{s}, r\right) Y=S, \\
a_{K X}\left(w, w_{s}, r\right) X+a_{K Y}\left(w, w_{s}, r\right) Y=K .
\end{gathered}
$$

In the specific-factors model we know even if the prices of the goods $\left(p_{x}, p_{y}\right)$ are the same as those prevailing in the global economy, local factor prices may differ from the global ones, since factor prices are not equalized if factor endowments in the economy are different from the rest of the world ${ }^{9}$.

In the following we assume that $w_{s}>w$; in particular, $w>w^{*}$ and $w_{s}>w_{s}^{*}$, where $w^{*}$ and $w_{s}^{*}$ denote wages in the foreign country. This assumption implies that the open developing economy is an immigration country. In our model, economic incentives are the key driver of immigration decisions. In the next section we explore the effect of immigration on relative income inequality. The higher value of $w_{s} / w$ stands for the relative higher wage inequality in the economy. A percentage change in an endogenous factor price is denoted by $d w / w=\hat{w}$. Therefore, a decrease in the wage gap between highly skilled and low skilled labor can be described by $\hat{w}_{s} / \hat{w}>1$.

\section{The Immigration of Talent and Low Skilled Labor}

Firstly, we examine the consequences of mobility of talent, i.e. immigration of skilled workers. In this case $S$ increases and $w_{s}$ decreases. Subsequent changes will follow in equilibrium:

$$
\hat{r}=-\frac{\theta_{S Y}}{\theta_{K Y}} \hat{w}_{S} \text { and } \hat{w}=\frac{\theta_{S Y}}{\theta_{K Y}} \cdot \frac{\theta_{K X}}{\theta_{L X}} \hat{w}_{S}
$$

where $\theta_{K Y}$ is the share of capital in production cost of $Y$, etc. as mentioned above. A decline in $w_{s}$, following the immigration of the talent, will increase $r$. Both wage rates, $w$ and $w_{s}$, are decreasing. Therefore immigration of talent leads to a change in income distribution within the economy.

Proposition 1. (Immigration of talent): As wages $w$, $w_{s}$ fall, the rental rate of capital $r$ increases. Wage inequality will be reduced if the wage rate $w_{s}$ decreases more than $w$, i.e. $\frac{\hat{w}_{s}}{\hat{w}}>1$. Immigration of skilled workers results in a decreasing wage inequality, if and

\footnotetext{
${ }^{9}$ For a discussion of the properties of the specific-factors model see, for example, Bhagwati et al., [17].
}

only if the capital's share in the $Y$ industry exceeds that in the industry $X$, i.e. $\theta_{K Y}>\theta_{K X}$. Whenever the factor intensities are reversed, wage inequality will increase.

Proof. Following condition (6) and using $\theta_{L X}=1-\theta_{K X}$ and $\theta_{S Y}=1-\theta_{K Y}$, we get $\frac{\hat{w}_{s}}{\hat{w}}>1$ if and only if $\theta_{K Y}>\theta_{K X}$.

Suppose that $P_{x}$ and $P_{y}$ remain constant, while the supply of talent increases by immigration, it follows that $\hat{r}>0>\hat{w}>\hat{w}_{s}$, if capital intensity in the immigration industry $Y$ exceeds that of non-immigration industry $X$, and $\hat{r}>0>\hat{w}_{s}>\hat{w}$ if $\theta_{K X}>\theta_{K Y}$.

Secondly we examine the consequences of immigration of low skilled labor. In this case $L$ increases and $w$ decreases. Subsequent changes will follow in equilibrium:

$$
\hat{r}=-\frac{\theta_{L X}}{\theta_{K X}} \hat{w} \text { and } \hat{w}_{S}=\frac{\theta_{L X}}{\theta_{K X}} \frac{\theta_{K Y}}{\theta_{S Y}} \hat{w} .
$$

We obtain

Proposition 2. (Immigration of low skilled workers): As wages $w$ and $w_{s}$ fall, the rental rate of capital $r$ increases. Wage inequality will be reduced, if the wage rate $w_{s}$ decreases more than $w$, i.e. $\frac{\hat{w}_{s}}{\hat{w}}>1$, if and only if $\theta_{K Y}>\theta_{K X}$. Immigration of low skilled workers results in a decreasing wage inequality if and only if the capital's share in the $Y$ industry exceeds that in industry $X$. Whenever the factor intensities are reversed, wage inequality will increase.

Proof. Following condition (7) and using $\theta_{L X}=1-\theta_{K X}$ and $\theta_{S Y}=1-\theta_{K Y}, \frac{\hat{w}_{S}}{\hat{w}}>1$ if and only if $\theta_{K Y}>\theta_{K X}$.

If $P_{x}$ and $P_{y}$ remain constant, while the supply of low skill labor increases by immigration, it follows that $\hat{r}>0>\hat{w}>\hat{w}_{s}$, if capital intensity in non-immigration industry $Y$ exceeds that of immigration industry $X$ and $\hat{r}>0>\hat{w}_{s}>\hat{w}$ if $\theta_{K X}>\theta_{K Y}$. Therefore, capital will gain in terms of both goods, while labor will lose in terms of both goods. The results of both propositions show that the effect on income and wage inequality depends on the degree of mobility and capital intensity in the immigration industry of the economy.

\section{Conclusions}

Immigration affects wages and decreasing wages in both sectors following immigration make labor the loser of the race for talents. Furthermore, immigration is affecting wage 
rates and the wage inequality in developing economies. This note shows that the impact of immigration of skilled or low skilled labor on the wage inequality depends on the capital intensity of the both sectors, the one in which workers immigrate and the second one on which the immigration has an downstream effect. It is often argued that immigration of low skilled workers contributes to increasing wage inequality. Taking into account the income share of capital in the different sectors we are able to show that this is true only if the low skilled labor using sector produces with relatively high capital intensity. However, agricultural sectors with a high demand for seasonal workers as well as services like domestic staff might be sectors with low capital endowment and intensity. So, seasonal workers and maids appear not to stress the wage inequality. On the contrary, using the specific-factors trade model, we find that immigration might reduce wage inequalities under rather realistic conditions.

Developing countries with often porous immigration schemes do not choose their migrants. Insofar the types of labor as well as its specific impact on wage inequalities matter in analyzing the short and medium-run effects of immigration. The results presented may shift the focus from the bounded consideration of the effect on the single wage towards the downstream effects on the other sector as well as on the wage gap. They reveal immigration being not the driving force behind the increasing wage inequality but behind the increasing income equality; further empirical studies are required.

Altogether, the winner of the race for talents are the capital holders benefiting from immigration.

\section{References}

[1] OECD, "Growing Unequal? Income Distribution and Poverty in OECD Countries," Organisation for Economic Co-operation and Development, Paris, 2008a.

[2] United Nations, International Migration, Department of Economic and Social Affairs, Wall Chart, New York. 2006.

[3] OECD, “The Global Competition for Talent, Mobility of the Highly Skilled," Organisation for Economic Cooperation and Development, Paris, 2008b.

[4] World Bank, "Reshaping Economic Geography," The World Bank, Washington, D.C., 2009.
[5] International Organization for Migration (IOM), "World Migration 2008: Managing Labour Mobility in the Evolving Global Economy,” Geneva, 2008.

[6] World Bank, "International Migration, Remittances and the Brain Drain," The World Bank, Washington, D.C., 2005.

[7] A. Kemnitz, "Can Immigrant Employment Alleviate the Demographic Burden? The Role of Union Centralization," Economics Letters, Vol. 99, No. 1,2005, pp. 123-126.

[8] International Labour Organization (ILO), "World of Work Report 2008: Income Inequalities in the Age of Financial Globalization,” Geneva, 2008.

[9] S. Yabuuchi and S. Chaudhuri, "International Migration of Labour and Skilled-Unskilled Wage Inequality in a Developing Economy,” Economic Modelling, Vol. 24, No. 1, 2007, pp. 128-137.

[10] S. Marjit, U. Broll and S. Sengupta, "Trade and Wage-Gap in Poor Countries: The Role of the Informal Sector,” In: A. Bose, Ed., Macroeconomics, Trade and Institutions, Essays in honour of M. K. Rakshit, Oxford University Press, Calcutta, 2000.

[11] S. Marjit and R. Acharyya, "International Trade, Wage Inequality and the Developing Economy,” Physica, Heidelberg, 2001.

[12] S. Marjit, H. Beladi and A. Chakrabarti, "Trade and Wage Inequality in Developing Countries," Economic Inquiry, Vol. 42, No. 2, 2004, pp. 295-303.

[13] S. Marjit and S. Kar, "Emigration and Wage Ineq- uality," Economics Letters, Vol. 88, No. 1, 2005, pp. 141-145.

[14] H. Johannsson and S. Weiler, "Immigration and Wage Inequality in the 1990s: Panel Evidence from the Current Population Survey,” Social Science Journal, Vol. 42, No. 2, 2005, pp. 231-240.

[15] R. W. Jones, "A Three-Factor Model in Theory, Trade, and History," In: J. N. Bhagwati, Ed., Trade, Balance of Payments, and Growth, Chapter 1, North-Holland, Amsterdam, 1971.

[16] J. Meckl and S. Zink, "Human-Capital Investment and the Wage Gap,” Economic Theory, Vol. 19, No. 4, 2002, pp. 853-859.

[17] J. N. Bhagwati, A. Panagariya and T. N. Srinivasan, "Lectures in International Trade,” 2nd Edition, MIT Press, Cambridge, 1998. 